\title{
Cyclodextrin-erythromycin complexes as a drug delivery device for orthopedic application
}

This article was published in the following Dove Press journal:

International Journal of Nanomedicine

7 December 201 I

Number of times this article has been viewed

\author{
Wei Song ${ }^{\prime}$ \\ Xiaowei Yu ${ }^{2}$ \\ Sunxi Wang ${ }^{5}$ \\ Ralph Blasier ${ }^{4}$ \\ David C Markel ${ }^{3}$ \\ Guangzhao $\mathrm{Mao}^{5}$ \\ Tong Shi' \\ Weiping Ren ${ }^{1,3}$
}

'Department of Biomedical Engineering, Wayne State University,

Detroit, MI, USA; ${ }^{2}$ Department

of Orthopedic Surgery, Second

Affiliated Hospital of Nanjing Medical

University, Nanjing, People's Republic

of China; ${ }^{3}$ Detroit Medical Center

and Providence Hospital Orthopedic

Residency, Detroit, ${ }^{4}$ Orthopedic

Section, St Francis Hospital,

Escanaba, ${ }^{5}$ Department of Chemical

Engineering, Wayne State University,

Detroit, MI, USA
Correspondence: Weiping Ren Department of Biomedical Engineering, Wayne State University College of Engineering, 818 W Hancock, Bioengineering Center, Detroit, MI 4820I, USA

Tel + I 3I35778I I8

Fax + I 3/3 5778333

Email as7606@wayne.edu
Background: Erythromycin, a hydrophobic antibiotic used to treat infectious diseases, is now gaining attention because of its anti-inflammatory effects and ability to inhibit osteoclasts formation. The aim of this study was to explore a cyclodextrin-erythromycin (CD-EM) complex for sustained treatment of orthopedic inflammation.

Methods and results: Erythromycin was reacted with $\beta$-cyclodextrin to form a nonhost-guest CD-EM complex using both kneading and stirring approaches. Physiochemical measurement data indicated that erythromycin and cyclodextrin formed a packing complex driven by intermolecular forces instead of a host-guest structure due to the limited space in the inner cavity of $\beta$-cyclodextrin. The CD-EM complex improved the stability of erythromycin in aqueous solution and had a longer duration of bactericidal activity than free erythromycin. Cytotoxicity and cell differentiation were evaluated in both murine MC3T3 preosteoblast cells and RAW 264.7 murine macrophage cells. The CD-EM complex was noncytotoxic and showed significant inhibition of osteoclast formation but had little effect on osteoblast viability and differentiation.

Conclusion: These attributes are especially important for the delivery of an adequate amount of erythromycin to the site of periprosthetic inflammation and reducing local inflammation in a sustained manner.

Keywords: erythromycin, cyclodextrin, drug stability, bactericidal activity, osteoclastogenesis

\section{Introduction}

Up to $20 \%$ of patients with total joint replacement will develop radiographic evidence of osteolysis and/or aseptic loosening. ${ }^{1-3}$ Aseptic loosening most likely results from an inflammatory response to billions of wear debris particles shed from the prosthesis during normal use. The interaction of macrophages with wear debris is the likely determinant of whether wear debris-induced inflammation will be resolved or progress to irreversible osteolysis/aseptic loosening. ${ }^{4}$ A recent approach to limiting osteolysis/ aseptic loosening has focused on inhibiting periprosthetic inflammation by pharmaceutical intervention. ${ }^{5-7}$

Erythromycin, a 14-member lactone ring macrolide antibiotic, has been used for the treatment of infectious diseases for the past 50 years. ${ }^{8}$ In the last decade, erythromycin has attracted a great deal of attention because of its additional anti-inflammatory effects at subantimicrobial doses..$^{9,10}$ An example of erythromycin used as an anti-inflammatory drug has been demonstrated recently in Japan, where erythromycin was successful in treating diffuse panbronchiolitis. ${ }^{11,12}$ Our previous studies have indicated that erythromycin is a promising treatment for osteolysis/aseptic loosening. First, erythromycin inhibited wear debris-induced osteoclastogenesis by inhibition of NF- $\kappa$ B activity in 
both a RAW264.7 macrophage cell line and in mouse bone marrow progenitor cells. ${ }^{13}$ Second, erythromycin inhibited wear debris-induced inflammatory osteolysis in a murine osteolysis model. ${ }^{14}$ Third, oral erythromycin $600 \mathrm{mg} /$ day reduced periprosthetic tissue inflammation in 32 patients with aseptic loosening who were candidates for surgical revision. ${ }^{15}$ Although we have demonstrated the efficacy of orally administered erythromycin in improving periprosthetic tissue inflammation, long-term systemic treatment with erythromycin is not recommended in view of the potential side effects, such as bacterial resistance, nausea, and vomiting. Therefore, it would be advantageous to restrict delivery of erythromycin to the inflammatory periprosthetic site. However, delivery to and maintenance of prolonged erythromycin release at the site of periprosthetic inflammation presents a considerable challenge. ${ }^{16}$ We propose that the efficiency of erythromycin delivered to a periprosthetic site can be increased by improving the chemical stability and water solubility of the drug. ${ }^{17,18}$

Cyclodextrins are cyclic oligomers of glucose that are molecular "carriers" with a hydrophilic exterior and a hydrophobic cavity. Cyclodextrins are biocompatible and do not elicit an immune response in humans. ${ }^{19}$ Cyclodextrins can be divided into three types, ie, $\alpha, \beta$, and $\gamma$ cyclodextrins, based on their number of glucose monomers. Cyclodextrins are used to improve drug bioavailability by increasing solubility and/or dissolution through inclusion of water-insoluble drugs (like erythromycin) into their hydrophobic cavities, ${ }^{20,21}$ improving drug stability, ${ }^{22-24}$ increasing the permeability of water-insoluble drugs, and reducing drug toxicity by making the drug effective at lower doses.

Cyclodextrin-drug complexes can be prepared in several ways. ${ }^{25}$ The most common procedure is to stir a mixture of cyclodextrins and drugs dissolved by two immiscible solvents vigorously. Another procedure is the so-called kneading method, which kneads cyclodextrins with drug components using a small amount of solvent. The physical force required to achieve the process of complex formation is favored energetically. Both methods could be used to prepare various kinds of water-insoluble drugs. ${ }^{26}$

Complex formation between cyclodextrin monomers and drug molecules via dynamic noncovalent interactions using the host-guest model has been well described. ${ }^{19}$ This model commonly involves using cyclodextrins as host molecules and attracting hydrophobic guest molecules, such as aromatic molecules, which are incorporated into the hydrophobic cavity of cyclodextrin through the formation of a hydrogen bond under thermodynamically favorable conditions. ${ }^{25}$
However, the roles of cyclodextrin and the drug molecules could be reversed during complex formation when the drug molecules are too large to be incorporated. ${ }^{27}$ Cyclodextrins act as nonhost molecules when forming complexes with cyclotetrachromotropylene ${ }^{28}$ and calcichrome. ${ }^{29}$ The formation of a host-guest complex is dependent on the dimensional match between the cyclodextrin cavity and the size of the guest molecule.

In this paper, we describe the synthesis and characterization of a cyclodextrin-erythromycin (CD-EM) complex prepared using both the stirring and kneading methods. The physiochemical properties (water solubility, stability, and CD-EM interaction) and biological activity (cellular behavior and bacterial inhibition) of the complex are described. We suggest that a CD-EM complex might potentially be applied to a prosthetic surface, with sustained release of erythromycin to prevent orthopedic infection and aseptic loosening.

\section{Materials and methods Materials}

Erythromycin, $\beta$-cyclodextrin, $\beta$-glycerophosphate, and a tartrate-resistant acid phosphatase (TRAP) assay kit were purchased from Sigma-Aldrich (St Louis, MO). An alkaline phosphatase (ALP) assay kit was obtained from BioVision (San Francisco, CA). Absolute alcohol (100\%) was purchased from Deconlab Inc (King of Prussia, PA). Sodium phosphate $\left(\mathrm{Na}_{2} \mathrm{CO}_{3}\right)$ and sodium hydroxide $(\mathrm{NaOH})$ were purchased from Fisher Scientific (Fair Lawn, NJ). Deuterium oxide $\left(\mathrm{D}_{2} \mathrm{O}\right)$ and methanol D4 were obtained from Cambridge Isotope Laboratories Inc (Andover, MA), and an $\alpha$-modified minimum essential medium, a live-dead cytotoxicity kit, and Dulbecco's modified Eagle's medium were purchased from Invitrogen (Camarillo, CA). Ascorbic acid was obtained from Sigma-Aldrich. Receptor activator of nuclear factor kappa-B ligand (RANKL) was purchased from Research Diagnostics Inc (Flanders, NJ). A lactate dehydrogenase assay kit was obtained from Roche Diagnostics GmbH (Mannheim, Germany). All chemicals used were of reagent grade.

\section{Preparation of CD-EM complex}

We used both a solvent evaporation method (MV) and a kneading method (MVI) to incorporate erythromycin into the hydrophobic cavity of $\beta$-cyclodextrin. ${ }^{30}$ For the MV method, erythromycin was first dissolved in $100 \%$ alcohol $(0.25 \mathrm{~g} / \mathrm{mL})$. Dropwise addition of erythromycin solution to the saturated $\mathrm{CD}-\mathrm{H}_{2} \mathrm{O}(0.125 \mathrm{~g} / \mathrm{mL})$ solution was done under constant stirring at $800 \mathrm{rpm}$ until the mixed solution was homogenous. Using the MVI method, the CD-EM 
complex was obtained by manually kneading a mixture of saturated cyclodextrin- $\mathrm{H}_{2} \mathrm{O} 0.125 \mathrm{~g} / \mathrm{mL}$ solution and erythromycin-alcohol $0.25 \mathrm{~g} / \mathrm{mL}$ at a molar ratio of $1: 1$ in a ceramic mortar for 3 hours. The complexes obtained by the MV and MVI methods were initially frozen at $-20^{\circ} \mathrm{C}$ overnight and lyophilized at $-30^{\circ} \mathrm{C}$ and $1.3 \times 10^{3} \mathrm{~Pa}$ overnight. Noninteracted erythromycin mixed with the complex was removed by rinsing twice with $100 \%$ alcohol. The CD-EM was collected by alcohol wash through a $0.8 \mu \mathrm{m}$ membrane filter (Millipore, Bedford, MA). Finally, the CD-EM complex was sterilized by exposure to ultraviolet light overnight. The sterilized CD-EM mixture was resuspended in sterile distilled water $(5 \mathrm{mg} / \mathrm{mL})$ just before testing.

\section{Measurement of erythromycin concentration}

Briefly, $100 \mu \mathrm{L}$ of the sample solution was mixed with $100 \mu \mathrm{L}$ of alkaline solution $(0.12 \mathrm{M} / \mathrm{L}$, sodium phosphate; $0.25 \mathrm{M} / \mathrm{L}$, sodium hydroxide) and incubated in a $60^{\circ} \mathrm{C}$ water bath for 15 minutes in order to cleave the macrocyclic lactone ring of erythromycin. ${ }^{31}$ After cooling to room temperature, the samples were read using an ultraviolet-visible spectrophotometer (BioTek Synergy HT, Winooski, VT) at OD $235 \mathrm{~nm}$. To calculate the erythromycin concentration, a standard erythromycin concentration curve was included in each sample measurement. The ratio of erythromycin and cyclodextrin incorporated into the CD-EM complex was reproducibly obtained and found to be about 1:3.3 (w/w) according to this quantification method.

\section{${ }^{1} \mathrm{H}-\mathrm{NMR}$ and ${ }^{13} \mathrm{C}-\mathrm{NMR}$ spectra analysis}

${ }^{1} \mathrm{H}$-nuclear magnetic resonance (NMR) experiments were performed on a Varian-500S spectrometer operating at a frequency of $500 \mathrm{mHz}$ and $25^{\circ} \mathrm{C}$ using a $5 \mathrm{~mm}$ AutoX-probe. One-dimensional ${ }^{1} \mathrm{H}-\mathrm{NMR}$ spectra were recorded, with a flip angle of $90^{\circ}$, a spectral width of $4000 \mathrm{~Hz}$, and 256 scans of $16 \mathrm{~K}$ points. Cyclodextrin $14 \mathrm{mg} / \mathrm{mL}$ and CD-EM $20 \mathrm{mg} / \mathrm{mL}$ samples were dissolved in $\mathrm{D}_{2} \mathrm{O}$, while erythromycin $6 \mathrm{mg} / \mathrm{mL}$ was first dissolved in methanol D4 and then mixed with $\mathrm{D}_{2} \mathrm{O}$. ${ }^{13} \mathrm{C}$-NMR experiments were also performed on the same instrument at a frequency of $500 \mathrm{mHz}$ and $37^{\circ} \mathrm{C}$ for 20 hours. Cyclodextrin $30 \mathrm{mg} / \mathrm{mL}$ and CD-EM $30 \mathrm{mg} / \mathrm{mL}$ samples were dissolved in $\mathrm{D}_{2} \mathrm{O}$ at $37^{\circ} \mathrm{C}$.

\section{X-ray diffractometry}

The crystalline structures and phases of cyclodextrin, erythromycin, and CD-EM (MV and MVI) were characterized using an x-ray diffractometer (Rigaku SmartLab,
Woodlands, TX). CuK $\alpha$ radiation $(\lambda=1.5418 \AA)$ was used to scan the diffraction angles $(2 \theta)$ between $5^{\circ}$ and $80^{\circ}$ at a speed of $5 \%$ minute. The spectra were compared with standard spectra from the JCPDS card via Jade 5 software in order to identify the sample phases and crystalline structures.

\section{Ultraviolet spectrometry}

Absorbance spectra of cyclodextrin, erythromycin, and CD-EM were obtained using an ultraviolet-visible spectrophotometer (BioTek Synergy HT). Briefly, $100 \mu \mathrm{L}$ of cyclodextrin, erythromycin, and CD-EM water solution $(10 \mathrm{mg} / \mathrm{mL})$ were placed in a 96-well ultraviolet plate (Fisher Scientific, Pittsburgh, PA) and mounted onto the spectrophotometer. A scanning wavelength range of 200-300 $\mathrm{nm}$ and a step size of $1 \mathrm{~nm}$ were set.

\section{Scanning electron microscopy}

The morphologies of the cyclodextrin, erythromycin, and CD-EM samples were characterized by scanning electron microscopy (SEM, Hitachi S-2400, Japan). All samples were coated with gold (Gold Sputter, EFFA coater, Redding, CA) before SEM analysis. Morphologies were viewed at a $25 \mathrm{kV}$ accelerating voltage.

\section{Stability of CD-EM}

Erythromycin was firstly dissolved in $100 \%$ of alcohol and then suspended in $5 \mathrm{~mL}$ of distilled water to make a concentration of $0.1 \mathrm{~g} / \mathrm{mL}$. CD-EM mixtures were also dissolved in $5 \mathrm{~mL}$ of distilled water to make a concentration of $0.43 \mathrm{~g} / \mathrm{mL}$. Both samples were incubated in a $37^{\circ} \mathrm{C}$ water bath for various time periods. A fraction of samples $(100 \mu \mathrm{L})$ was collected at different time points $(0,3,5,7,9,12,14,16,18$, and 20 hours $)$. These samples were filtered through syringe filters (Minisart, Sartorius Stedim North America Inc, Bohemia, NY) with a pore size of $0.45 \mu \mathrm{m}$. The filtrates (excluding the undissolved CD-EM complex) were then used to measure the erythromycin concentration. The percentage of measurable erythromycin was plotted against the predefined time points.

\section{Antibacterial activity assay}

A modified minimum inhibitory concentration assay was developed to measure the bactericidal activity of erythromycin released from the CD-EM conjugate. First, a Mueller-Hinton broth inoculated with Staphylococcus aureus at a concentration of $1-2 \times 10^{8}$ colony forming units $/ \mathrm{mL}$ (OD reading at $625 \mathrm{~nm}$ around $0.08-0.1$ ) was prepared. The bacterial suspension was then mixed with a known concentration of free erythromycin $(64 \mu \mathrm{g} / \mathrm{mL})$, free cyclodextrin 
(148 $\mu \mathrm{g} / \mathrm{mL}$ ), and CD-EM (cyclodextrin $212 \mu \mathrm{g} / \mathrm{mL}$, erythromycin $64 \mu \mathrm{g} / \mathrm{mL}$ ) separately and incubated at $37^{\circ} \mathrm{C}$ for approximately 160 hours. Bactericidal activity was evaluated by dynamic measurement of OD reading at different time points. Bacterial culture suspension in the absence of erythromycin was included as a positive control. In a separate experiment, the bactericidal activity of the CD-EM complex at different concentrations $(0,53,106,159$, and $212 \mu \mathrm{g} / \mathrm{mL})$ was evaluated for up to 24 hours in culture.

\section{Effect of CD-EM complex on osteoblastic ALP activity}

Mouse MC3T3-E1 preosteoblasts (American Type Culture Collection, CRL-2593) were plated at a density of $1 \times 10^{4}$ cells/well in a 12 -well plate and cultured in $\alpha$-modified minimum essential medium supplemented with $10 \%$ fetal bovine serum and a $1 \%(\mathrm{v} / \mathrm{v})$ antibiotic mixture of penicillin and streptomycin at $37^{\circ} \mathrm{C}$ in a humidified incubator with $5 \%$ $\mathrm{CO}_{2}$ for 24 hours. The MC3T3-E1 cells were then cultured in cell differentiation medium ( $\alpha$-modified minimum essential medium supplemented with ascorbic acid $50 \mu \mathrm{g} / \mathrm{mL}$ and $\beta$-glycerophosphate $10 \mathrm{mM}$ ) for 16 days in the presence of erythromycin $(1.6 \mathrm{mg} / \mathrm{mL}$ and $16 \mu \mathrm{g} / \mathrm{mL})$, cyclodextrin (3.7 $\mathrm{mg} / \mathrm{mL}$ and $37 \mu \mathrm{g} / \mathrm{mL}$ ) and CD-EM $(5.3 \mathrm{mg} / \mathrm{mL}$ and $53 \mu \mathrm{g} / \mathrm{mL})$, respectively. Culture media and drugs were replaced every 3 days until the predetermined dates. The collected culture media were used for cytotoxicity assay.

Sixteen days after culture, the culture media was removed and the cell monolayer was gently washed twice with ice-cold phosphate-buffered saline. The cell lysates were homogenized with ALP assay buffer (200 $\mu \mathrm{L} /$ well), followed by centrifugation $(14,000 \times \mathrm{g}$ for 5 minutes $)$ to remove insoluble material. ALP activity in the cell lysate samples was measured at OD $405 \mathrm{~nm}$ (UVmax colorimeter, Molecular Devices, Sunnyvale, CA) with an ALP assay kit. ALP activity was expressed in nanomoles of p-nitrophenol produced per minute per microgram of protein. All experiments were conducted in duplicate and repeated in three independent experiments.

\section{Effects of CD-EM complex on osteoclast formation}

Osteoclasts were generated from a murine RAW 264.7 macrophage cell line in the presence of RANKL. ${ }^{32}$ RAW 264.7 cells were maintained in Dulbecco's modified Eagle's medium containing $10 \%$ fetal bovine serum and antibiotics (100 U/mL of penicillin $\mathrm{G}$ and $100 \mu \mathrm{g} / \mathrm{mL}$ of streptomycin) at $37^{\circ} \mathrm{C}$ in a humidified incubator with $5 \% \mathrm{CO}_{2}$.
To investigate the effects of erythromycin released from the CD-EM conjugate on osteoclast formation, RAW cells were cultured in the presence of RANKL $50 \mathrm{ng} / \mathrm{mL}$ for up to 7 days in the presence of erythromycin $16 \mu \mathrm{g} / \mathrm{mL}$, cyclodextrin $37 \mu \mathrm{g} / \mathrm{mL}$, and CD-EM $53 \mu \mathrm{g} / \mathrm{mL}$. Culture media and drugs were replaced every 3 days. The collected cultured media at each time point were used for cytotoxicity assay.

TRAP staining was performed using a commercial kit as described elsewhere. ${ }^{14}$ In brief, RAW cells were fixed in $4 \%$ paraformaldehyde, followed by incubation at $37^{\circ} \mathrm{C}$ for 1 hour in a solution of naphthol AS-BI phosphoric acid, fast garnet GBC, and sodium tartrate. Following a rinse in deionized water, images of the stained cells were captured at $10 \times$ by a microscope (Carl Zeiss MicroImaging, Thornwood, NY). The mean percentage of $\mathrm{TRAP}^{+}$cells was calculated by reading the stained plate at $525 \mathrm{~nm}$ in the ultraviolet-visible spectrophotometer through the built-in protocol.

\section{Cytotoxicity assay}

Cell toxicity was determined by measuring the release of lactate dehydrogenase from dead or dying cells into the culture medium using a colorimetric method following the manufacturer's instructions. Blank culture medium was used as a control. Lactate dehydrogenase (LDH) activity was expressed as absorbance (OD) per mg protein. In addition, the potential cellular toxicity in cells treated with higher doses of erythromycin $(1.6 \mathrm{mg} / \mathrm{mL})$, cyclodextrin $(3.7 \mathrm{mg} / \mathrm{mL})$, and CD-EM $(5.3 \mathrm{mg} / \mathrm{mL})$ were evaluated using the LiveDead ${ }^{\circledR}$ viability/cytotoxicity staining kit (Invitrogen, Camarillo, CA).

\section{Statistical analysis}

The statistical analysis was performed using the analysis of variance test, with the Schafer formula for post hoc multiple comparisons using the SPSS software package version 7.5 (SPSS Inc, Chicago, IL). All treatments were performed in triplicate. Data were expressed as the mean \pm standard error of the mean. A $P$ value $<0.05$ was considered to be statistically significant.

\section{Results and discussion 'H-NMR}

The ${ }^{1} \mathrm{H}-\mathrm{NMR}$ spectrum results demonstrated the presence of erythromycin in the CD-EM composite (Figure 1). Seven glucose units with identical conformations and hexagonal symmetry can be identified in Figure $1 \mathrm{~A}$ by locating the integral peaks of $1-6$ protons. ${ }^{33}$ The ${ }^{1} \mathrm{H}-\mathrm{NMR}$ spectrum of erythromycin in Figure 1B can be identified, consistent with earlier observations. ${ }^{34}$ The CD-EM complex prepared by both 

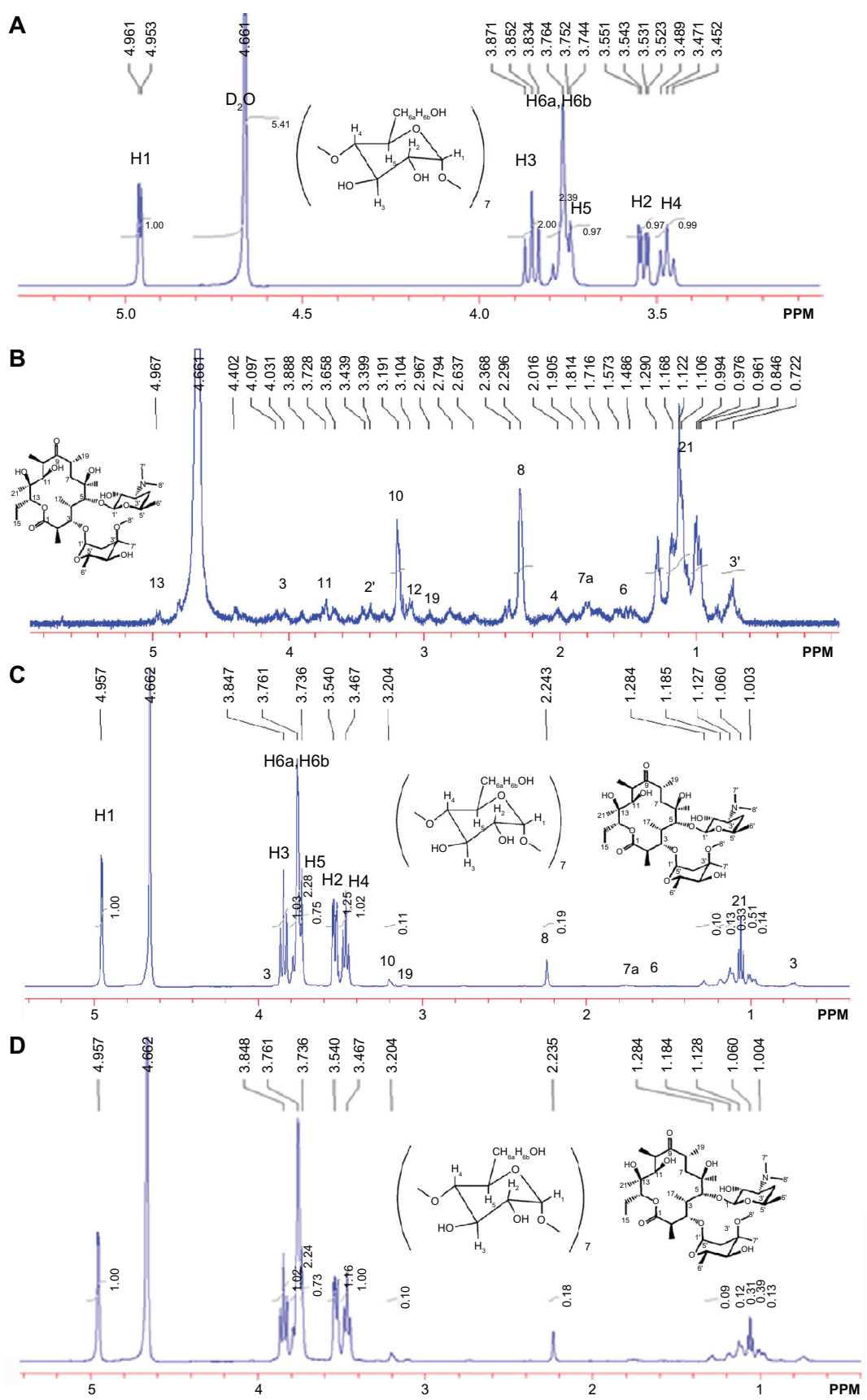

Figure I $500 \mathrm{mHz}$ 'H-NMR spectra at $25^{\circ} \mathrm{C}$ of (A) cyclodextrin $14 \mathrm{mg}$ (B) erythromycin $6 \mathrm{mg}$ (C) cyclodextrin-erythromycin $20 \mathrm{mg}$ (MV) (7/3, w/w) complex, (D) $20 \mathrm{mg}$ of cyclodextrin-erythromycin $(\mathrm{MVI})(7 / 3, \mathrm{w} / \mathrm{w})$ complex in $750 \mu \mathrm{L}$ of $\mathrm{D}_{2} \mathrm{O}$ ranging from 0.5 to $5.5 \mathrm{ppm}$. Important proton chemical shifts and peak integrations of solutes are labeled.

Abbreviations: MV, method V; MVI, method VI.

the MV and MVI methods has the same spectral pattern, as shown in Figure $1 \mathrm{C}$ and D. The ${ }^{13} \mathrm{C}-\mathrm{NMR}$ spectrum results also demonstrate the presence of erythromycin in the CD-EM complex (Figure 2). ${ }^{13} \mathrm{C}$ signals for cyclodextrin at $\delta=101.884$, $81.202,73.150,72.143,71.906$, and $60.394 \mathrm{ppm}$ were the localization of $\mathrm{C} 1, \mathrm{C} 2, \mathrm{C} 3, \mathrm{C} 4, \mathrm{C} 5$, and $\mathrm{C} 6$, respectively, in $\mathrm{D}_{2} \mathrm{O}$. The CD-EM spectra (MV and MVI) showed a similar pattern, with a minor chemical shift $(0.008 \mathrm{ppm})$ to a lower field only from $\mathrm{C} 1$ and $\mathrm{C} 6$ and carbon peaks at $\delta=57$ and 16 ppm from erythromycin molecules.

The interaction between cyclodextrin and guest molecule occurs when guest molecule approaches the nonpolar cavity of cyclodextrin, which causes an upfield chemical shift $(-\delta)$ of guest molecule protons and a downfield chemical shift $(\delta)$ of host molecule carbons. ${ }^{35}$ Steric hindrance is known to be the decisive factor for preventing formation of a cyclodextrin-drug 


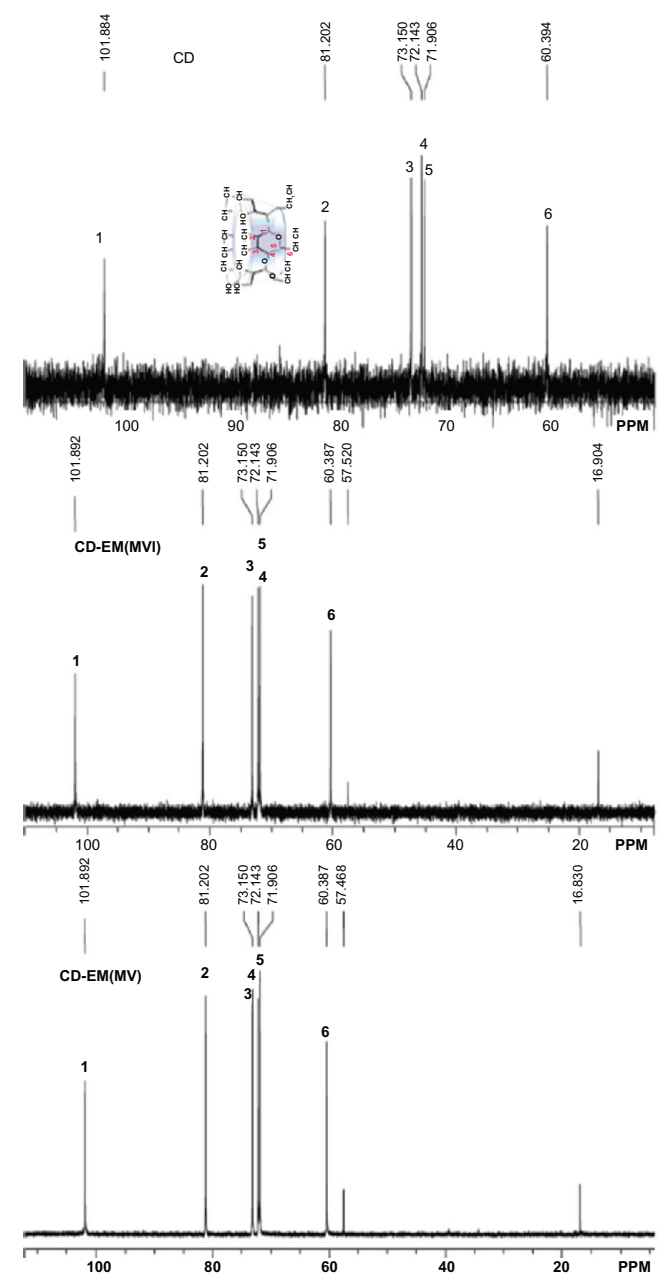

Figure $2500 \mathrm{mHz}{ }^{13} \mathrm{C}-\mathrm{NMR}$ spectra at $37^{\circ} \mathrm{C}$ of $30 \mathrm{mg}$ of cyclodextrin, $30 \mathrm{mg}$ of cyclodextrin-erythromycin (MV) $(7 / 3, \mathrm{w} / \mathrm{w})$ complex, $30 \mathrm{mg}$ of cyclodextrinerythromycin $(\mathrm{MVI})(7 / 3, \mathrm{w} / \mathrm{w})$ complex in I $\mathrm{mL}$ of $\mathrm{D}_{2} \mathrm{O}$. Important carbons $(\mathrm{Cl}-\mathrm{C} 6$ and $C$ from erythromycin) chemical shifts and peak integrations of solutes are labeled. Abbreviations: CD, cyclodextrin; CD-EM, cyclodextrin-erythromycin; MV, method V; MVI, method VI.

complex as a host-guest model. ${ }^{36}$ The large macrocyclic lactone ring structure in erythromycin is geometrically incompatible with the cavity dimensions of $\beta$-cyclodextrin. However, a nonhost-guest formation between cyclodextrin and erythromycin could be driven thermodynamically.

A selection of chemical shift variations obtained for erythromycin from its free form to a complex form with cyclodextrin is presented in Table 1. Chemical shift variations from protons of erythromycin in the presence of cyclodextrin indicate the formation of a complex, especially protons $\left(7^{\prime}, 8\right.$, and 21$)$ at the edge of the erythromycin molecules with larger shifts, which are attributed to the anisotropic shielding effect of the cyclodextrin cavity. However, other unaffected protons $\left(3^{\prime}, 4,6,12,10\right.$, and 19) of erythromycin indicate that the erythromycin molecule did not enter the cyclodextrin cavity. Instead, the shifts of protons ( $7^{\prime}$ and 8 ) directed outwards on two sugar units (L-cladinose and D-desosamine) indicate interaction of these two sugar units with the cyclodextrin molecules, while the shift of proton (21) from the diagonal position on the macrocyclic ring indicates the approach of another cyclodextrin molecule. Moreover, the shifts of $\mathrm{C} 1$ and C6, although minor, indicate a cyclodextrin molecule approaching erythromycin on the smaller side of the cavity. There is no evidence of inclusion of the macrolide in the cyclodextrin cavity because there is no chemical shift of $\mathrm{C} 2$, $\mathrm{C} 3, \mathrm{C} 4$, and $\mathrm{C} 5$ from the ${ }^{13} \mathrm{C}-\mathrm{NMR}$ spectra. The formation of an intermolecular hydrogen bond between cyclodextrin and the guest molecules would ordinarily cause larger chemical shift variations $(\delta>0.05)$ of cyclodextrin protons, particularly the $\mathrm{H}_{3}$ and $\mathrm{H}_{5}$ directed inside the cyclodextrin cavity. However, the chemical shift for cyclodextrin after complex formation shows no significant variations $(\delta<0.01)$, demonstrating the absence of hydrogen bond formation between cyclodextrin and erythromycin. Several assumptions have been made to interpret the interaction force during CD-drug complex formation, including Van der Waals interactions, ${ }^{37}$ hydrogen bonding, ${ }^{38}$ and release of strain energy in the ring of the cyclodextrin molecule. ${ }^{39}$ Some aromatic molecules have been found to be able to be included in the cyclodextrin cavity by forming a hydrogen bond with $\mathrm{H}^{3}$ and $\mathrm{H}^{5} \cdot{ }^{35}$ However, the interactive force between nonaromatic molecules of supermolecular size and cyclodextrin when forming a nonhost-guest complex is still controversial. Intermolecular Van der Waals forces and hydrophobic interactions are hypothesized to be the dominant driving forces for the formation of a cyclodextrin-drug complex..$^{40}$ On the basis of the chemical shift of both cyclodextrin and erythromycin, we predict that the two sugar units and the diagonal position of erythromycin interacted with three cyclodextrin molecules via Van der Waals forces to form a packed complex. The three-dimensional topologic structure of the CD-EM complex is shown in Figure 3.

\section{X-ray diffraction}

Formation of the complex was found to alter the original crystal lattice of cyclodextrin and subsequently the x-ray diffraction

Table I A Proton chemical shift of cyclodextrin

\begin{tabular}{lllllll}
\hline Proton & HI & H2 & H3 & H4 & H5 & H6 \\
\hline Free-CD & 4.953 & 3.543 & 3.852 & $3.47 I$ & 3.744 & 3.764 \\
CD-EM (MV) & $4.95 \mathrm{I}$ & 3.540 & 3.847 & 3.467 & 3.736 & $3.76 \mathrm{I}$ \\
CD-EM (MVI) & $4.95 \mathrm{I}$ & 3.540 & 3.848 & 3.467 & 3.736 & $3.76 \mathrm{I}$ \\
$\delta(\mathrm{MV})$ & -0.002 & -0.003 & -0.005 & -0.004 & -0.008 & -0.003 \\
$\delta(\mathrm{MVI})$ & -0.002 & -0.003 & -0.004 & -0.004 & -0.008 & -0.003 \\
\hline
\end{tabular}

Abbreviations: CD, cyclodextrin; CD-EM, cyclodextrin-erythromycin; MV, method V; MVI, method VI. 
Table IB Proton chemical shift of erythromycin

\begin{tabular}{llllllllll}
\hline Proton & $\mathbf{3}^{\prime}$ & $\mathbf{4}$ & $\mathbf{6}$ & $\mathbf{7}^{\prime}$ & $\mathbf{8}$ & $\mathbf{1 0}$ & $\mathbf{1 2}$ & $\mathbf{1 9}$ & $\mathbf{2 1}$ \\
\hline Free EM & 0.722 & 2.016 & 1.486 & 1.814 & 2.296 & 3.191 & 3.104 & 2.967 & 1.122 \\
MV & 0.734 & 2.014 & 1.488 & 1.785 & 2.243 & 3.204 & 3.110 & 2.961 & 1.060 \\
$M V I$ & 0.736 & 2.014 & 1.492 & 1.783 & 2.235 & 3.204 & 3.112 & 2.968 & 1.060 \\
$\delta(\mathrm{MV})$ & +0.012 & -0.002 & +0.002 & -0.029 & -0.053 & +0.013 & +0.006 & -0.005 & $-\mathbf{0 . 0 6 2}$ \\
$\delta(\mathrm{MVI})$ & +0.014 & -0.002 & +0.006 & $-\mathbf{0 . 0 3 1}$ & $-\mathbf{0 . 0 6 I}$ & +0.013 & +0.008 & +0.001 & $-\mathbf{0 . 0 6 2}$ \\
\hline
\end{tabular}

Note: Chemical shift variations with significance were specified in bold type.

Abbreviations: EM, erythromycin; MV, method V; MVI, method VI.

pattern. ${ }^{41}$ The x-ray diffraction spectra of cyclodextrin, CD-EM (MV and MVI), and erythromycin are shown in Figure 4. The spectrum of cyclodextrin indicates high crystallinity in cyclodextrin due to the characteristic sharp peaks at (041), (141), (180), (042), (162), (222), (223), and (044). The spectrum of erythromycin shows low crystallinity with numerous weaker intensity peaks and some amorphous curves, even though the (100), (021), (060), (070), and (121) planes were identified to match with the standard spectrum of erythromycin. Both spectra of CD-EM (MV and MVI) showed a pattern similar to cyclodextrin, but with distinct peaks at (220), (250), (231), and (062), and a red color different from that in the cyclodextrin spectrum. Moreover, the original peaks at (042), (251), (223), and (044) with a blue color had disappeared and the double peaks at (130) merged into a single peak in the CD-EM complex spectra. Some characteristic peaks of erythromycin [(060) and (121) with yellow color] were also seen in the CD-EM spectra. Generally, the spectra of CD-EM (MV) and CD-EM (MVI) were identical, with only some minor differences.

As new crystalline peaks were shown in spectra of CD-EM, phase transition for CD-EM complex during preparation process could be predicted. The conversion of a crystalline type for cyclodextrin and erythromycin revealed the formation of new complex. The intermolecular interaction of erythromycin and cyclodextrin could interrupt the original organization of cyclodextrin molecules and reformed crystalline lattices.

\section{Ultraviolet-visible spectrometry}

Formation of the cyclodextrin complex was also found to alter the original ultraviolet absorption spectrum. ${ }^{25}$ The ultraviolet

Table IC Carbon chemical shift of cyclodextrin

\begin{tabular}{lllllll}
\hline Carbon & CI & C2 & C3 & C4 & C5 & C6 \\
\hline Free-CD & 101.884 & 81.202 & 73.150 & 72.143 & 71.906 & 60.394 \\
CD-EM (MV) & $\mathbf{1 0 1 . 8 9 2}$ & 81.202 & 73.150 & 72.143 & 71.906 & $\mathbf{6 0 . 3 8 7}$ \\
CD-EM (MVI) & $\mathbf{1 0 1 . 8 9 2}$ & 81.202 & 73.150 & 72.143 & 71.906 & $\mathbf{6 0 . 3 8 7}$ \\
$\delta(\mathrm{MV})$ & $\mathbf{0 . 0 0 8}$ & 0 & 0 & 0 & 0 & $\mathbf{0 . 0 0 7}$ \\
$\delta(\mathrm{MVI})$ & $\mathbf{0 . 0 0 8}$ & 0 & 0 & 0 & 0 & $\mathbf{0 . 0 0 7}$ \\
\hline
\end{tabular}

Note: Chemical shift variations with significance were specified in bold type.

Abbreviations: EM, erythromycin; CD, cyclodextrin ; MV, method V; MVI, method VI. absorption spectral change on forming the CD-EM complex can be observed in Figure 5. The absorption peak was detected at $205 \mathrm{~nm}$ for free erythromycin. Absorption at $230 \mathrm{~nm}$ is consistent with a literature report for macrocyclic lactone. For the CD-EM complex, the presence of these two absorption peaks indicates the erythromycin substrate. A slight shift of the absorption peak for CD-EM from $205 \mathrm{~nm}$ to $200 \mathrm{~nm}$ can be interpreted as the effect of partial shielding of the excitable electrons in the cavity of cyclodextrin, while the shift of absorption from $230 \mathrm{~nm}$ to $235 \mathrm{~nm}$ is a bathochromic shift that usually happens after formation of a cyclodextrin complex. ${ }^{25}$

\section{SEM analysis}

To elucidate the formation of a CD-EM complex, morphologic observation was performed using high-resolution SEM. Figure 6 shows this for cyclodextrin (6A, D), erythromycin (6B, E), and CD-EM (6C, F). A monoclinic morphology of a cyclodextrin precipitate was observed under SEM (Figure 6A and D) and this was consistent with analytic results from $x$-ray diffraction and literature reports, ${ }^{42}$ while erythromycin powder was shown to be a semicrystalline precipitate (Figure 6B and E). Both the kneading and stirring processes facilitated interaction of cyclodextrin and erythromycin, altering their original crystalline structures and amorphization during freeze-drying, as shown in Figure 6C and F. For CD-EM prepared by both the MV and MVI methods, an appropriate

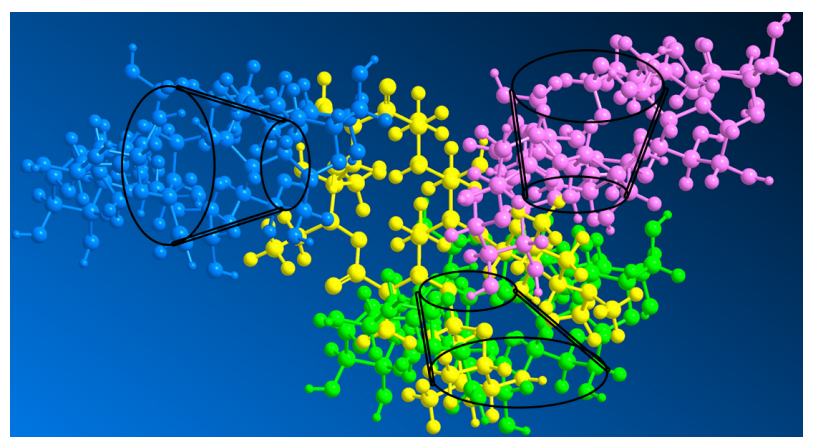

Figure 3 Three-dimensional molecular structure of cyclodextrin-erythromycin complex. Yellow, erythromycin; pink, cyclodextrin I; green, cyclodextrin 2; blue, cyclodextrin 3. 


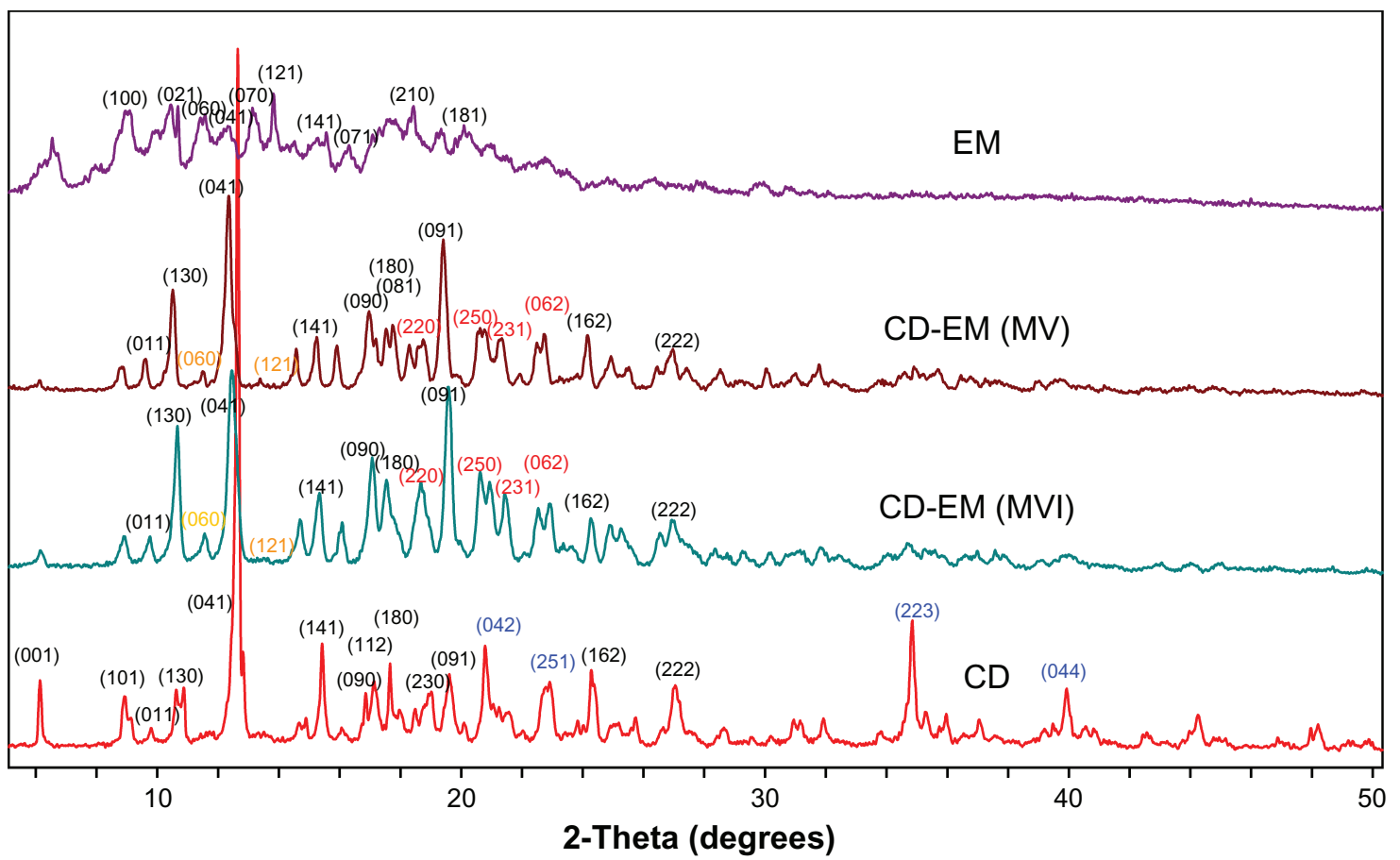

Figure $4 \mathrm{X}$-ray diffraction spectra for pure cyclodextrin, cyclodextrin-erythromycin (MV and MVI) before freeze-drying, and pure erythromycin. The $\mathrm{Y}$ axis (counts) of the diffraction pattern is vertically offset for clarity. Blue-peaks disappeared in spectra of CD-EM complex. Red-new peaks in spectra of CD-EM complex. Yellow-characteristic peaks of EM in in spectra of CD-EM complex.

Abbreviations: $C D$, cyclodextrin; EM, erythromycin; MV, method V; MVI, method VI.

water content initiated the CD-EM interaction as well as cyclodextrin matrix formation. The continuous phase of the cyclodextrin matrix stabilized the interactive erythromycin molecule, leading to aggregation of CD-EM precipitates. ${ }^{31}$

\section{Drug stability assay}

Decomposition of delivered drug, occurring within the initial period of implantation, is one of the main limitations of local drug delivery approaches, particularly for periprosthetic drug

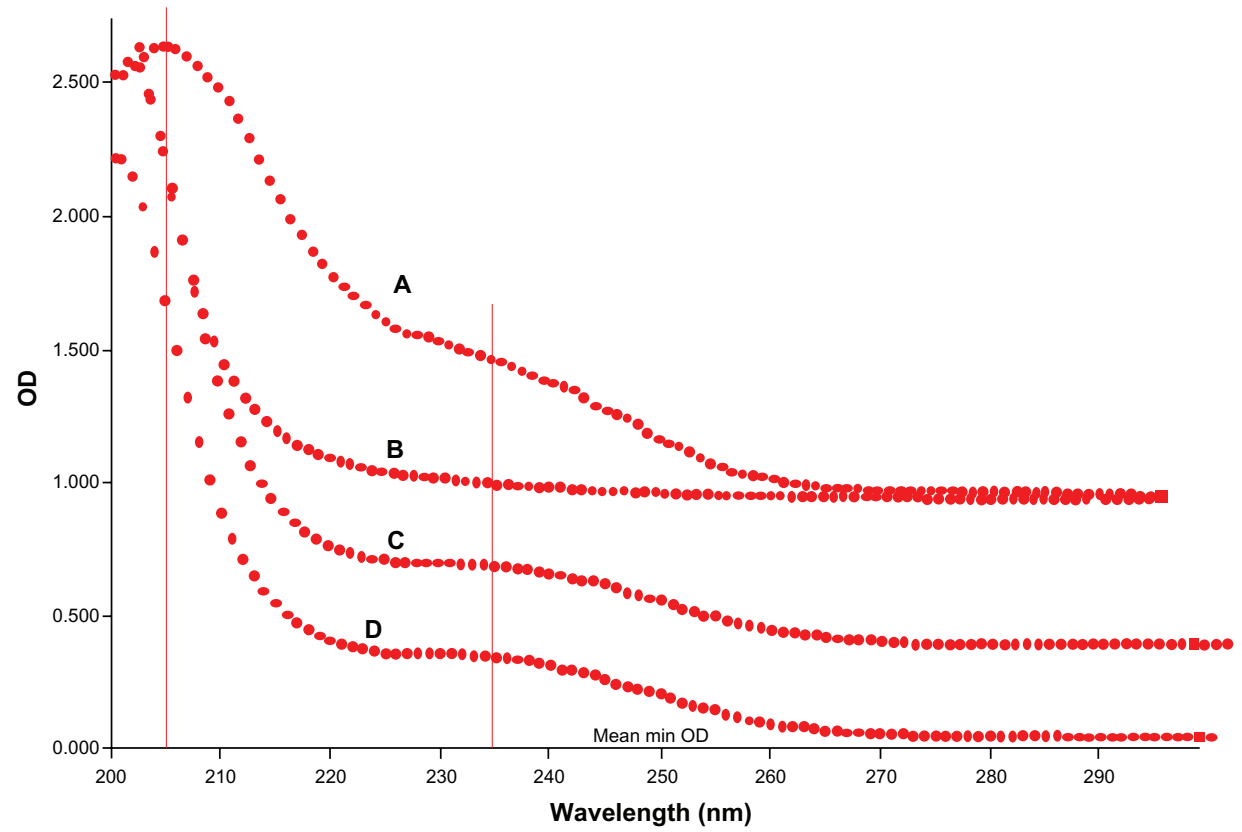

Figure 5 Ultraviolet spectra of (A) pure erythromycin, (B) pure cyclodextrin, (C) cyclodextrin-erythromycin (MV), and (D) cyclodextrin-erythromycin (MVI) from 200 nm to $300 \mathrm{~nm}$ with a step size of I $\mathrm{nm}$.

Abbreviations: MV, method V; MVI, method VI. 

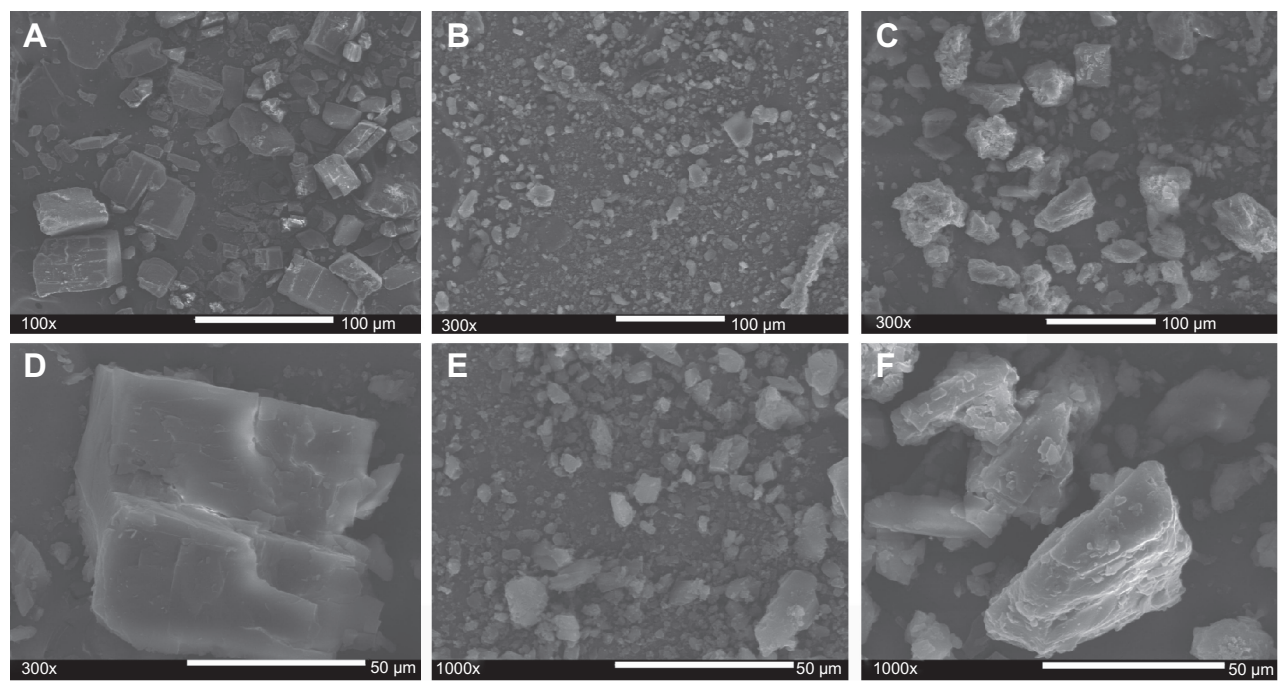

Figure 6 Scanning electron microscopic morphologies of (A, 100×; D, 300x) cyclodextrin, (B, 300×; E, 1000x) erythromycin and (C, 300x; F, 1000×) cyclodextrinerythromycin (MVI).

Abbreviation: MVI, method VI.

delivery. ${ }^{43-45}$ The formation of a cyclodextrin-drug complex aims to extend the duration of drug activity in an aqueous environment. In this assay, the concentration of erythromycin was dynamically decreased at $37^{\circ} \mathrm{C}$ over 20 hours for both pure erythromycin and CD-EM, as shown in Figure 7. The dramatic decrease of measurable erythromycin from about $90 \%$ to $50 \%$ took place after incubation for 6 hours. However, the fitting curves indicated that the rate of decrease of CD-EM was slower than for pure erythromycin, especially after 6 hours of incubation. At each time point after 6 hours, the percentages of measurable erythromycin from CD-EM were all higher than from pure erythromycin, indicating better stability. The invalidation of erythromycin in aqueous solution was susceptible to decomposition of the large macrocyclic lactone ring structure during the hydrolytic process. ${ }^{46}$ Protection of the integrity of the molecular structure of erythromycin in aqueous solution would help to increase its lifespan. By either the kneading or stirring method, formation of a CD-EM complex could provide a shielding effect for the erythromycin molecule from the surrounding cyclodextrin molecules, as described earlier. The packed cyclodextrin molecules improved the solubility of erythromycin in aqueous solution and stabilized its molecular structure by preventing attack from nucleophiles during hydrolysis. Nonetheless, the noncovalent interaction between cyclodextrin and erythromycin enables release of entrapped free erythromycin when the surrounding cyclodextrin becomes unstable.

\section{Bactericidal activity}

Erythromycin, one of the macrolide antibiotics, has been used to treat infectious diseases for more than 50 years. The molecular mechanism of its bactericidal activity is believed to involve binding to the 50s subunit of the bacterial 70s rRNA complex to interfere with aminoacyl translocation. Erythromycin is susceptible to loss of bactericidal activity in an acidic environment. ${ }^{46}$ We aimed to extend the bactericidal activity of erythromycin by embedding the drug in cyclodextrin nanoparticles. As shown in Figure 8, the results of a semiquantitative bactericidal activity assay show that bacterial growth was inhibited by treatment with the CD-EM complex in a dose-dependent manner (0-212 $\mu \mathrm{g} /$ $\mathrm{mL}$ ). This suggests that incorporation of erythromycin into cyclodextrin did not affect the bactericidal activity of erythromycin. To determine whether the CD-EM complex has

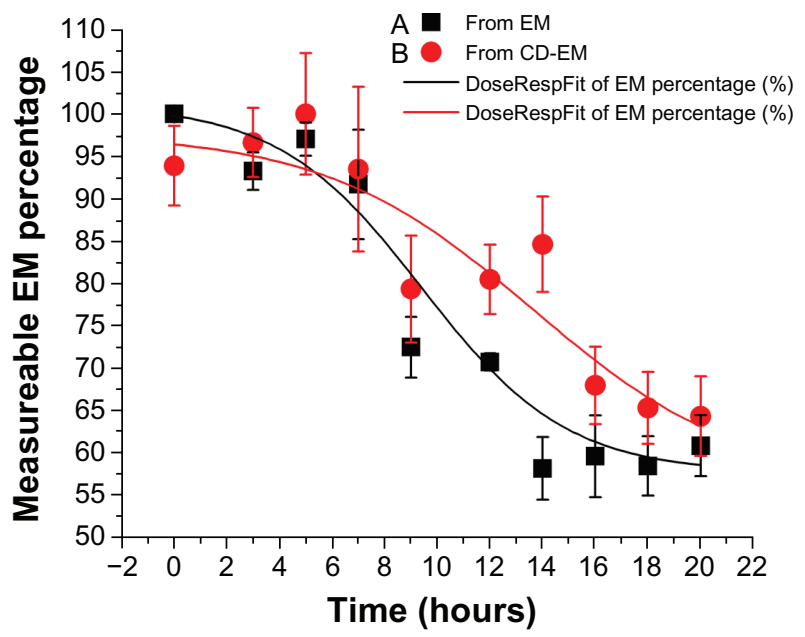

Figure 7 Drug stability profiles of $(\mathbf{A})$ erythromycin and (B) cyclodextrin-

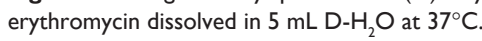

Note: Measurable percentage of erythromycin against time; $n=3$.

Abbreviations: $C D$, cyclodextrin; EM, erythromycin. 
longer bactericidal activity than free erythromycin, we repeated our bactericidal activity measurements in the presence of either the CD-EM complex $(212 \mu \mathrm{g} / \mathrm{mL}$, including erythromycin $64 \mu \mathrm{g} / \mathrm{mL}$ ) or the same amount of free erythromycin for up to 170 hours (Figure $8 \mathrm{~B}$ ). We found that treatment with both erythromycin and CD-EM resulted in persistent bacterial growth inhibition for up to 170 hours. Based on an exponentially fitting curve analysis, the bactericidal activity of CD-EM was sustained for longer than for free erythromycin at the same dose. These data indicate that erythromycin has longer durability and bactericidal activity in aqueous solution when interacted with cyclodextrin, as compared with free erythromycin molecules.

\section{Effect of CD-EM complex on osteoblastic viability and differentiation}

To assess the efficacy of the CD-EM complex, it was important to show that the complex was noncytotoxic and had no
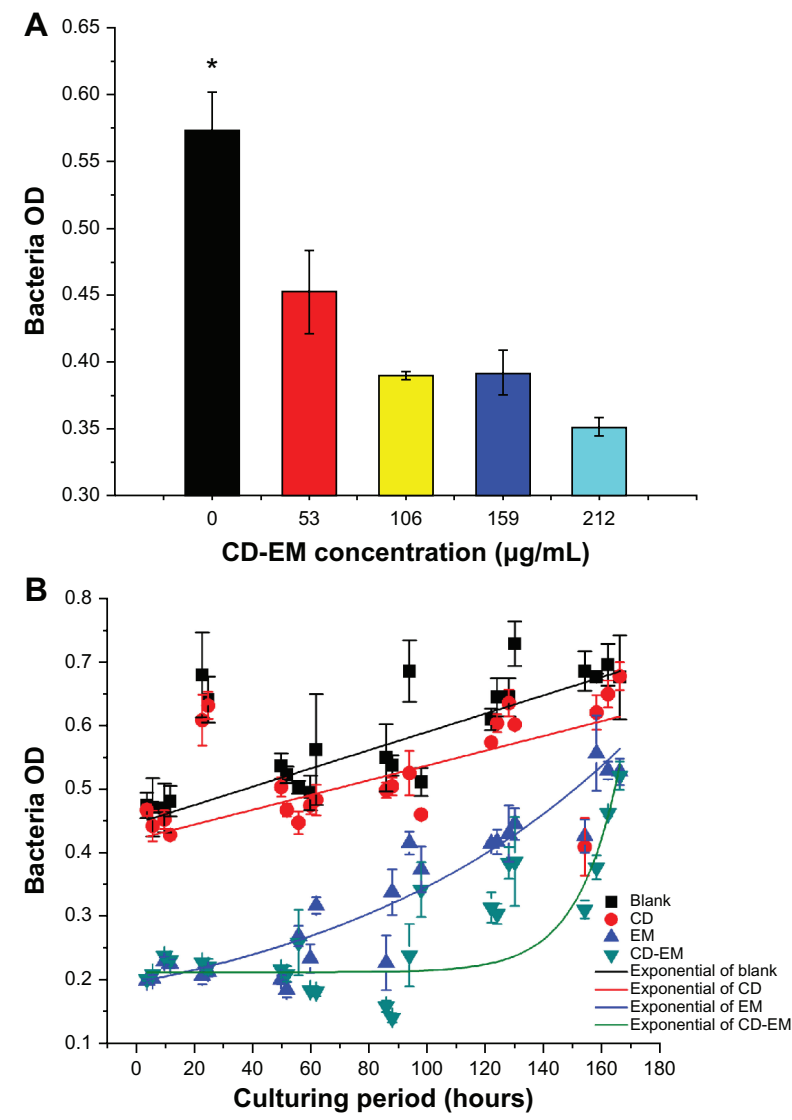

Figure 8 Bactericidal effect assay. (A) Semiquantitative bacteria growth inhibition assay in $2 \mathrm{~mL}$ broth in the presence of cyclodextrin-erythromycin with gradient concentrations $(53,106,159$, and $212 \mu \mathrm{g} / \mathrm{mL}$ ) for 24 hours, respectively. (B) Semiquantitative bacteria growth inhibition assay in $2 \mathrm{~mL}$ broth in the presence of erythromycin $64 \mu \mathrm{g} / \mathrm{mL}$, cyclodextrin $148 \mu \mathrm{g} / \mathrm{mL}$, and cyclodextrin-EM $212 \mu \mathrm{g} / \mathrm{mL}$ at predetermined time points, respectively.

Notes: All dots were exponentially fitted; $P<0.05$ related to 0 versus 159 and $212 \mu \mathrm{g} / \mathrm{mL} ; \mathrm{n}=4$.

Abbreviations: $C D$, cyclodextrin; EM, erythromycin. inhibitory effect on osteoblast differentiation. In addition, it was critical to define the safe and optimal dosage of erythromycin. The free cyclodextrin concentration was based on the amount of cyclodextrin present in the CD-EM complex at the indicated erythromycin concentration. For example, the highest concentration of erythromycin $(1.6 \mathrm{mg} / \mathrm{mL})$ is equivalent to approximately $5.3 \mathrm{mg} / \mathrm{mL}$ of CD-EM complex. Therefore, $3.7 \mathrm{mg} / \mathrm{mL}$ of free cyclodextrin was used as the control. As shown in Figure 9A, free cyclodextrin, erythromycin, and the CD-EM complex did not show appreciable cytotoxicity in MC3T3 cells at erythromycin concentrations up to $1.6 \mathrm{mg} / \mathrm{mL}$ for a treatment period of 16 days, based on the live/dead cell staining assay. Intracellular ALP activity was measured to determine the effect of the CD-EM complex on osteoblast differentiation. As shown in Figure 9B, treatment with erythromycin $1.6 \mathrm{mg} / \mathrm{mL}$, cyclodextrin $3.7 \mathrm{mg} / \mathrm{mL}$, and CD-EM $5.3 \mathrm{mg} / \mathrm{mL}$ all inhibited ALP activity significantly after 16 days in culture. We noticed that cyclodextrin $3.7 \mathrm{mg} / \mathrm{mL}$ achieved stronger inhibition of ALP activity than did erythromycin, while cells treated with the CD-EM complex showed the lowest ALP activity, although the difference was not statistically significant. Inhibition of ALP activity was closely related to the dose chosen. Our data demonstrated that MC3T3 cells treated with a lower concentration of cyclodextrin $(37 \mu \mathrm{g} / \mathrm{mL})$, erythromycin $(16 \mu \mathrm{g} / \mathrm{mL})$, or CD-EM complex $(53 \mu \mathrm{g} / \mathrm{mL})$ showed a slight increase in ALP activity compared with untreated cells (Figure 9B). This finding that a lower dose of CD-EM complex (with erythromycin $16 \mu \mathrm{g} / \mathrm{mL}$ ) slightly increased ALP activity is important, because it will help us to design a safe and optimal range of drug loading for a periprosthetic drug delivery device. Our previous studies have indicated that erythromycin released from a periprosthetic device has bactericidal activity at a concentration of $10 \mu \mathrm{g} / \mathrm{mL}$ or less. ${ }^{16}$ We have also noticed that treatment with erythromycin at a low concentration ( $5 \mu \mathrm{g} / \mathrm{mL}$ or less) leads to significant anti-inflammatory activity and inhibitory effect on osteoclast formation. ${ }^{13}$

Considering these facts and the data presented here, a high concentration of CD-EM complex drug loading is unnecessary and should be avoided in future experiments. More efforts are required to optimize the drug loading dose and the dynamics of drug release.

\section{Effect of the CD-EM complex on osteoclastogenesis}

Recent studies have shown that RANKL and macrophage colony-stimulating factor are sufficient to induce differentiation 

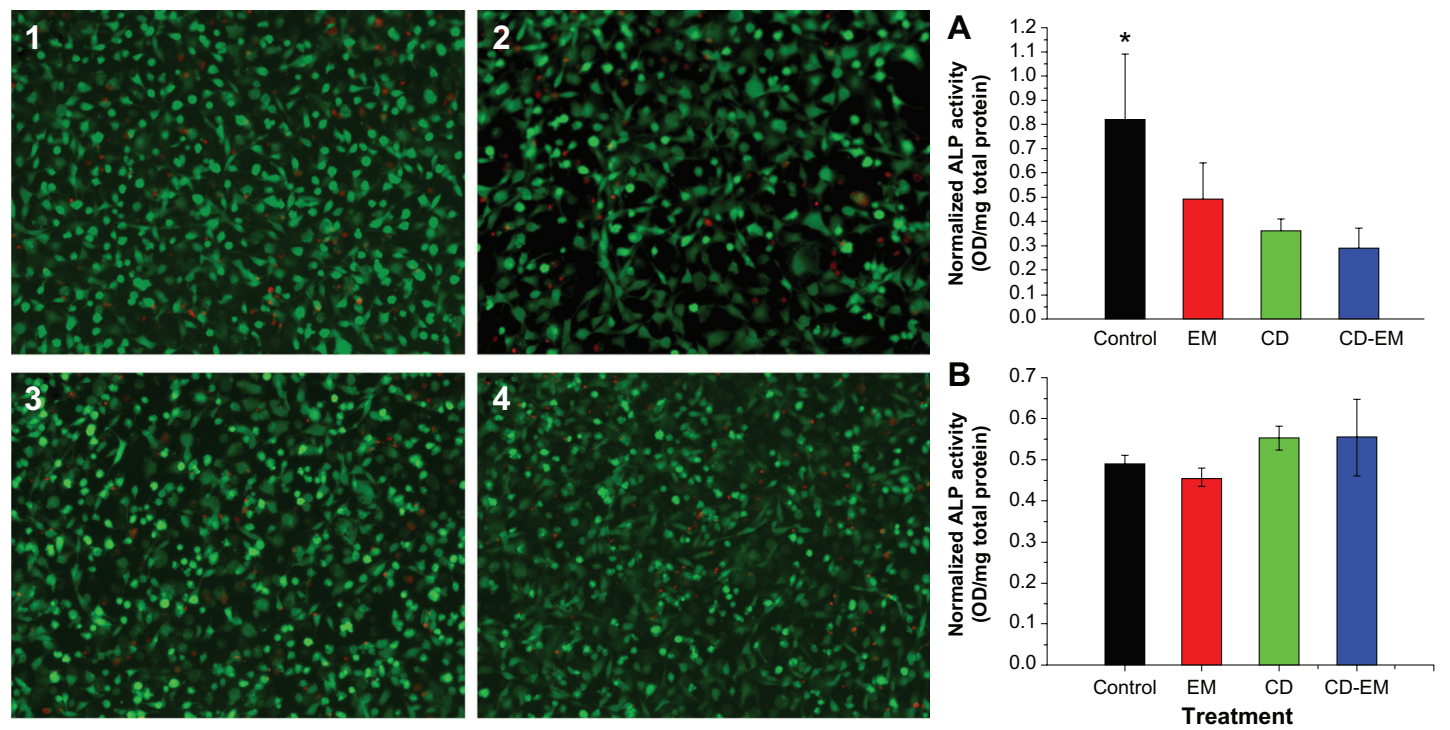

Figure 9 MC-3T3 cell activity assay. The live (green)-dead (red) staining (original magnification, $\times 50$ ) of MC3T3 cells cultured for 16 days in the presence of (2) erythromycin $1.6 \mathrm{mg} / \mathrm{mL}$, (3) cyclodextrin $3.7 \mathrm{mg} / \mathrm{mL}$, and (4) cyclodextrin-erythromycin $5.3 \mathrm{mg} / \mathrm{mL}$. ALP activity of MC-3T3 cells cultured under the same conditions in the presence of drugs with $(\mathbf{A})$ higher concentrations of erythromycin $(1.6 \mathrm{mg} / \mathrm{mL})$, cyclodextrin $(3.7 \mathrm{mg} / \mathrm{mL})$, and cyclodextrin-erythromycin $(5.3 \mathrm{mg} / \mathrm{mL})$ and $(\mathbf{B})$ lower concentrations of erythromycin $(16 \mu \mathrm{g} / \mathrm{mL})$, cyclodextrin $(37 \mu \mathrm{g} / \mathrm{mL})$, and cyclodextrin-erythromycin $(53 \mu \mathrm{g} / \mathrm{mL})$.

Note: $* \mathrm{P}<0.05$ related to control versus cyclodextrin and cyclodextrin-erythromycin; $\mathrm{n}=6$.

Abbreviations: ALP, alkaline phosphatase; CD, cyclodextrin; EM, erythromycin.

of bone marrow osteoclast progenitors into mature osteoclasts in vitro in the absence of stromal cells. ${ }^{47,48}$ There is accumulating evidence to indicate that enhanced osteoclast formation and activity is a hallmark of aseptic loosening/ osteolysis. ${ }^{49-52}$ Our previous studies have indicated that erythromycin is a promising osteoclast inhibitor targeting the NF-kB signaling pathway. ${ }^{13}$ To determine whether the CD-EM complex retains inhibitory activity against osteoclast formation, we cultured RAW 264.7 osteoclast precursor cells in the continuous presence of RANKL with or without CD-EM complex for 7 days. As seen in Figure 10, $\mathrm{TRAP}^{+}$cells were developed in the presence of RANKL. Multinucleated (more than three nuclei) TRAP $^{+}$ cells were counted as osteoclasts (Figure 10B). Mononuclear $\mathrm{TRAP}^{+}$cells were counted as preosteoclasts (Figure 10C). ${ }^{13}$ Treatment with both erythromycin $16 \mu \mathrm{g} / \mathrm{mL}$ and an equivalent CD-EM complex significantly decreased the number of TRAP ${ }^{+}$cells (Figure 10C and E). However, treatment with free cyclodextrin had no inhibitory effect on the formation of $\mathrm{TRAP}^{+}$cells (Figure 10D). Quantitative analysis of the percentage of $\mathrm{TRAP}^{+}$cells in each well is summarized in the histogram shown in Figure 10. Through quantification results, we noticed that free erythromycin showed a better (albeit not statistically significant) inhibitory effect on the formation of TRAP ${ }^{+}$cells than did the CD-EM complex, which had a significant inhibitory effect on osteoclastogenesis. However, inhibition of formation of giant multinuclear cells by erythromycin and CE-EM showed a negligible difference. The mechanism involved needs to be investigated further. Nevertheless, our data indicate that the inhibitory effects of erythromycin are well preserved in the CD-EM complex.

\section{Cytotoxicity of CD-EM complex in MC3T3 and RAW 264.7 cells}

Although cyclodextrins are pharmaceutical excipients approved by the US Food and Drug Administration and expected to be safe for use, ${ }^{53}$ it is important to show that the CD-EM complex is not cytotoxic. Measurement of lactate dehydrogenase activity in culture medium is an indicator of increased permeability of the plasma membrane as a result of cytotoxicity. As shown in Figure 11A, treatment with free CD $3.7 \mathrm{mg} / \mathrm{mL}$, erythromycin $1.6 \mathrm{mg} / \mathrm{mL}$, or CD-EM $5.3 \mathrm{mg} / \mathrm{mL}$ did not show noticeable cytotoxicity in MC3T3 cells for up to 16 days. In addition, no significant increase in lactate dehydrogenase activity was found in RAW 264.7 cells with the same treatment as described for the MC3T3 cells up to 7 days (Figure 11B). The mechanism of the slight increase in lactate dehydrogenase activity observed in all RANKLtreated cells at day 4 is not clear. After 7 days in culture, we could not find any difference in lactate dehydrogenase activity between cells treated and not treated with CD-EM, indicating that the CD-EM complex is not cytotoxic to this cell line, even at a very high concentration. 

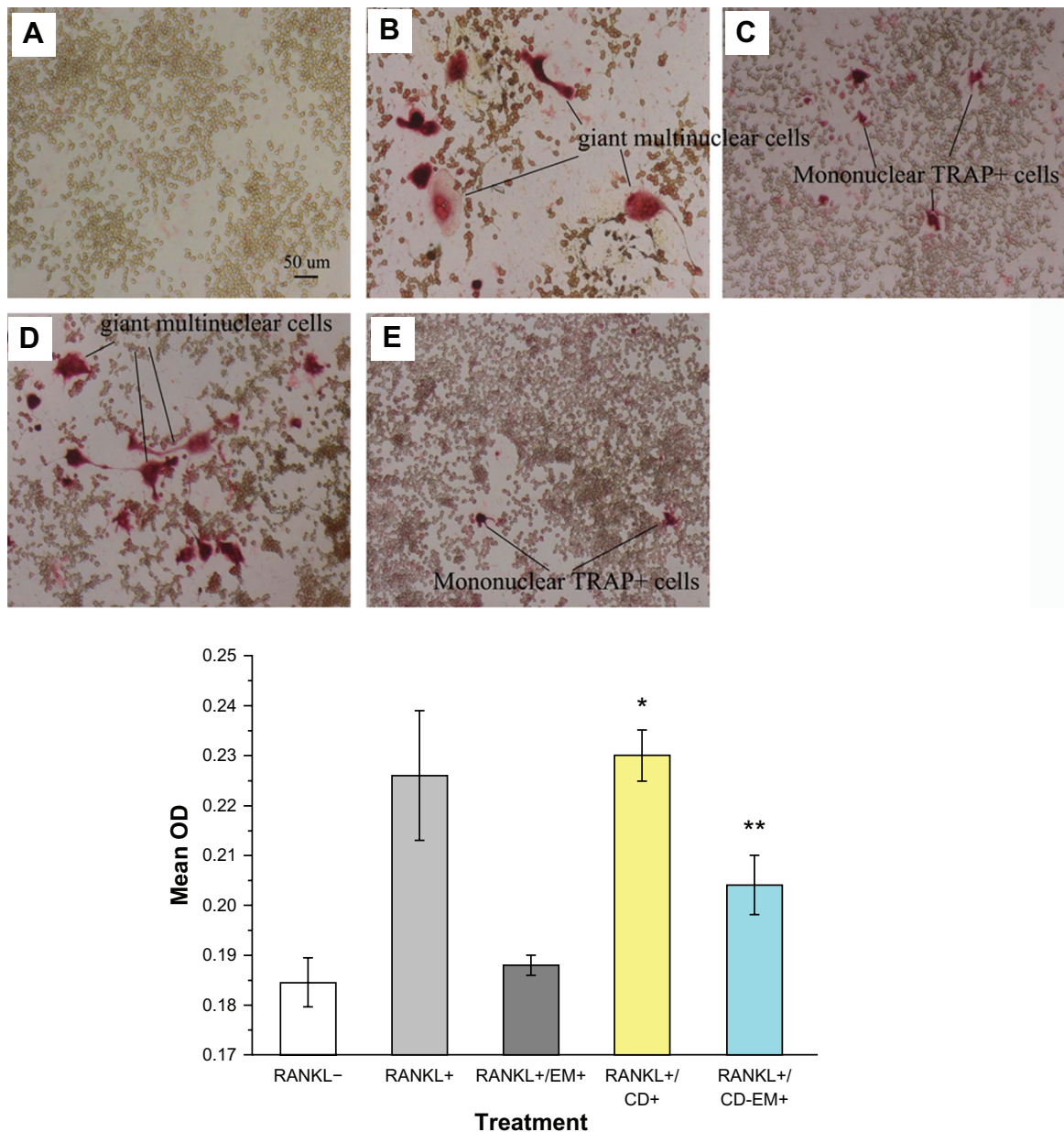

Figure 10 Erythromycin inhibits the amount of RANKL-induced TRAP' cell formation in murine RAW 264.7 cells. (A-E) Representative TRAP staining (original magnification, $\times 100$ ): (A) RANKL (-); (B) RANKL (+); (C) RANKL (+) + erythromycin (16 $\mu \mathrm{g} / \mathrm{mL})$; (D) RANKL (+) + cyclodextrin (37 $\mu \mathrm{g} / \mathrm{mL})$; and (E) RANKL $(+)+$ cyclodextrin-erythromycin $(53 \mu \mathrm{g} / \mathrm{mL})$. TRAP ${ }^{+}$cells were quantified by Image Analysis software (bottom panel). The value represents TRAP ${ }^{+}$cells location quantified as area percentage of TRAP $^{+}$cells (\%). Values represent averages of triplicate cultures from one representative experiment.

Notes: Using analysis of variance, $* P<0.05$ refers to RANKL $(+)+$ cyclodextrin $37 \mu g / \mathrm{mL}$ versus RANKL $(-)$, RANKL $(+)+$ erythromycin $16 \mu g / \mathrm{mL}$, and RANKL $(+)+$ cyclodextrin-erythromycin $53 \mu \mathrm{g} / \mathrm{mL}$; ${ }^{* *} P<0.05$ related to RANKL (+) + cyclodextrin-erythromycin $53 \mu \mathrm{g} / \mathrm{mL}$ versus RANKL $(-) ; \mathrm{n}=3$.

Abbreviations: $C D$, cyclodextrin; EM, erythromycin; RANKL, receptor activator of nuclear factor kappa-B ligand.
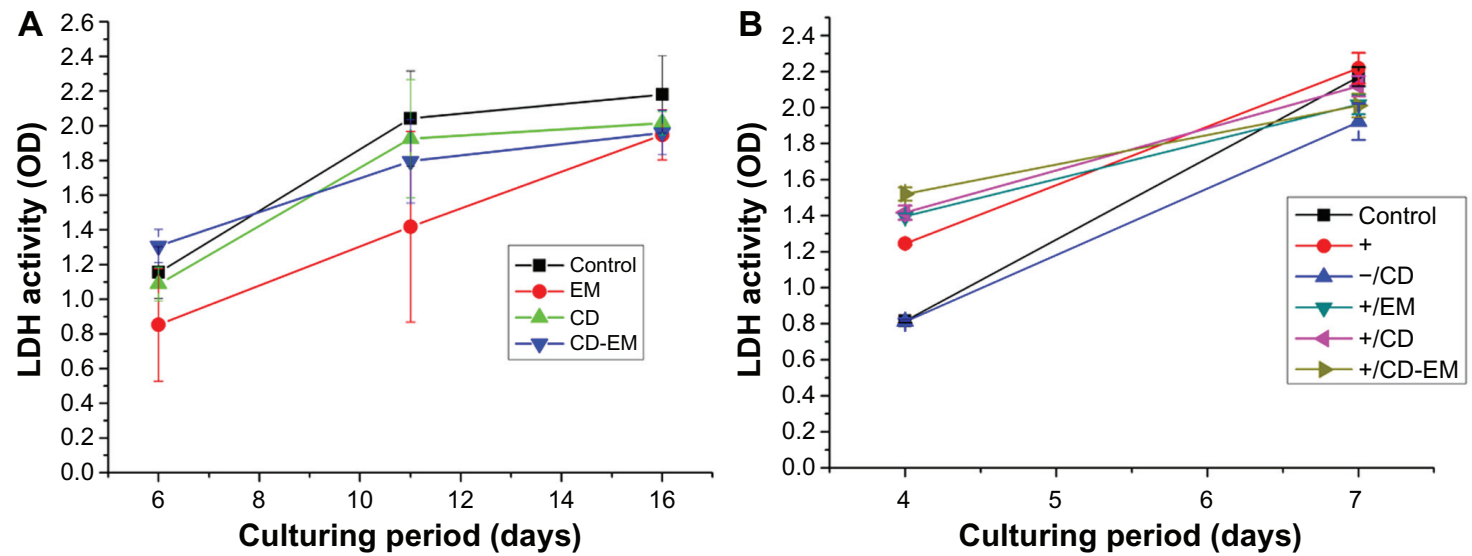

Figure II Lactate dehydrogenase activity in (A) culture medium of MC-3T3 cells after drug treatment [higher concentrations of erythromycin (I.6 mg/mL), cyclodextrin $(3.7 \mathrm{mg} / \mathrm{mL})$, and cyclodextrin-erythromycin $(5.3 \mathrm{mg} / \mathrm{mL})]$ for $6, I \mathrm{I}$, and 16 days, $n=6 ;(B)$ in culture medium of RAW 264.7 cells after drug treatment [lower concentrations of erythromycin ( $1.6 \mathrm{ug} / \mathrm{mL})$, cyclodextrin $(3.7 \mathrm{ug} / \mathrm{mL})$, and cyclodextrin-erythromycin $(5.3 \mathrm{ug} / \mathrm{mL})$ ] for 4 and 7 days, $\mathrm{n}=3$.

Note: The values shown are the mean \pm standard error of the mean from six observations.

Abbreviations: $C D$, cyclodextrin; EM, erythromycin; LDH, lactate dehydrogenase. 


\section{Conclusion}

Our study results indicate that the hydrophobic erythromycin molecule can interact with $\beta$-cyclodextrin via either the kneading or cogrinding method to form a nonhost-guest CD-EM complex. We found that the intermolecular packing structure of the CD-EM complex enabled extended stability in aqueous solution, durable bactericidal activity, an inhibitory effect on osteoclastogenesis with little effect on osteoblastic viability and differentiation, and safety with no cytotoxicity. These attributes are especially important in delivering a sufficient amount of erythromycin to the site of periprosthetic inflammation and reducing local inflammation in a sustained manner.

\section{Acknowledgments}

This work was supported by an institutional research grant from Sinai-Grace Hospital, Detroit Medical Center, and the National Natural Science Foundation of China (81071487). We would like to acknowledge Sunxi Wang and Dr Mao for sample characterization.

\section{Disclosure}

The authors report no conflicts of interest in this work.

\section{References}

1. Berry DJ, Harmsen WS, Cabanela ME, Morrey BF. Twenty-five-year survivorship of two thousand consecutive primary Charnley total hip replacements: Factors affecting survivorship of acetabular and femoral components. J Bone Joint Surg Am. 2002;84(2):171-177.

2. Keener JD, Callaghan JJ, Goetz DD, Pederson DR, Sullivan PM, Johnston RC. Twenty-five-year results after Charnley total hip arthroplasty in patients less than fifty years old: a concise follow-up of a previous report. J Bone Joint Surg Am. 2003;85A(6):1066-1072.

3. Fender D, Harper WM, Gregg PJ. Outcome of Charnley total hip replacement across a single health region in England: the results at five years from a regional hip register. J Bone Joint Surg Br. 1999;81(4):577-581.

4. Sethi RK, Neavyn MJ, Rubash HE, Shanbhag AS. Macrophage response to cross-linked and conventional UHMWPE. Biomaterials. 2003;24(15): 2561-2573.

5. Schwarz EM. What potential biologic treatments are available for osteolysis? J Am Acad Orthop Surg. 2008;(16 Suppl 1):S72-S75.

6. Pollice PF, Rosier RN, Looney RJ, Puzas JE, Schwarz EM, O’Keefe RJ. Oral pentoxifylline inhibits release of tumor necrosis factor-alpha from human peripheral blood monocytes: a potential treatment for aseptic loosening of total joint components. J Bone Joint Surg Am. 2001;83A(7):1057-1061.

7. Childs LM, Goater JJ, O’Keefe RJ, Schwarz EM. Efficacy of etanercept for wear debris-induced osteolysis. J Bone Miner Res. 2001;16(2): 338-347.

8. Yatsunami J, Hayashi S. Fourteen-membered ring macrolides as antiangiogenic compounds. Anticancer Res. 2001;21(6B):4253-4258.

9. Cervin A. The anti-inflammatory effect of erythromycin and its derivatives, with special reference to nasal polyposis and chronic sinusitis. Acta Otolaryngol. 2001;121(1):83-92.

10. Giamarellos-Bourboulis EJ. Macrolides beyond the conventional antimicrobials: a class of potent immunomodulators. Int J Antimicrob Agents. 2008;31(1):12-20.
11. Kudoh S. Erythromycin treatment in diffuse panbronchiolitis. Curr Opin Pulm Med. 1998;4(2):116-121.

12. Kudoh S, Azuma A, Yamamoto M, Izumi T, Ando M. Improvement of survival in patients with diffuse panbronchiolitis treated with lowdose erythromycin. Am J Respir Crit Care Med. 1998;157(6 Pt 1): 1829-1832.

13. Ren WP, Li XY, Chen BD, Wooley PH. Erythromycin inhibits wear debris-induced osteoclastogenesis by modulation of murine macrophage NFkB activity. J Orthop Res. 2004;22(1):21-29.

14. Ren WP, Bin W, Mayton L, Wooley PH. Erythromycin (EM) inhibits wear debris-induced inflammatory osteolysis in a murine model. J Orthop Res. 2006;24(2):280-290.

15. Ren W, Blasier R, Peng X, Shi T, Wooley PH, Markel D. Effect of oral erythromycin therapy in patients with aseptic loosening of joint prostheses. Bone. 2009;44(4):671-677.

16. Ren W, Zhang R, Hawkins M, Shi T, Markel DC. Efficacy of periprosthetic erythromycin delivery for wear debris-induced inflammation and osteolysis. Inflamm Res. 2010;59(12):1091-1097.

17. Khabriev RU, Popkov VA, Reshetnyak VY, Krasnyuk II. Solubility of erythromicin from solid dispersions. Pharm Chem J. 2009;43(11): 36-43.

18. Jayaraman SC, Ramachandran C, Weiner N. Topical delivery of erythromycin from various formulations: an in vivo hairless mouse study. J Pharm Sci. 1996;85(10):1082-1084

19. Davis ME, Brewster ME. Cyclodextrin-based pharmaceutics: past, present and future. Nat Rev Drug Discov. 2004;3(12):1023-1035.

20. Shimpi S, Chauhan B, Shimpi P. Cyclodextrins: application in different routes of drug administration. Acta Pharm. 2005;55(2):139-156.

21. Liu XM, Wiswall AT, Rutledge JE, et al. Osteotropic beta-cyclodextrin for local bone regeneration. Biomaterials. 2008;29(11):1686-1692.

22. Ferrari F, Sorrenti M, Rossi S, et al. Vancomycin-triacetyl cyclodextrin interaction products for prolonged drug delivery. Pharm Dev Technol. 2008;13(1):65-73.

23. Song 1, X, Du FY, Guo XQ, Pan SZ. Formation, characterization, and thermal degradation behavior of a novel tricomponent aggregate of beta-cyclodextrin, ferrocene, and polypropylene glycol. J Phys Chem B. 2010;114(4):1738-1744.

24. Matilainen L, Maunu SL, Pajander J, et al. The stability and dissolution properties of solid glucagon/gamma-cyclodextrin powder. Eur J Pharm Sci. 2009;36(4-5):412-420.

25. Szejtli J. Cyclodextrins and Their Inclusion Complex. 2nd ed. Budapest, Hungary: Akademiai Kiado; 1982.

26. Lafont F, Tran Van NG, Hanada K, Sansonetti P, van der Goot FG Initial steps of Shigella infection depend on the cholesterol/sphingolipid raft-mediated CD44-IpaB interaction. EMBO J. 2002;21(17): 4449-4457.

27. Poh BL, Thee KK. No distinction between host and guest - the case of cyclodextrins complexing with disodium 1,8-disulfonato3,4,5,6-acridinetetracarboxylic acid. Tetrahedron Lett. 1996;37(41): 7433-7436.

28. Poh BL, Tan CM. Complexation of amino-acids by cyclotetrachromotropylene in aqueous-solution - importance of ch-pi and pi-pi interactions. Tetrahedron. 1994;50(11):3453-3462.

29. Poh BL. Cyclodextrins (alpha-, beta-, and gamma-) as guests to calcichrome (calcion) in water. Tetrahedron. 1996;52(33):10979-10984.

30. Wongmekiat A, Tozuka Y, Moribe K, Oguchi T, Yamamoto K Preparation of drug nanoparticles by co-grinding with cyclodextrin: formation mechanism and factors affecting nanoparticle formation. Chem Pharm Bull (Tokyo). 2007;55(3):359-363.

31. Florey C. Analytical Profiles of Drug Substances. New York, NY: Academic Press Inc; 1979.

32. Yan T, Riggs BL, Boyle WJ, Khosla S. Regulation of osteoclastogenesis and RANK expression by TGF-beta1. J Cell Biochem. 2001;83(2): 320-325.

33. Wood DJ, Hruska FE, Saenger W. H-1 NMR-study of inclusion of aromatic-molecules in alpha-cyclodextrin. J Am Chem Soc. 1977;99(6): 1735-1740. 
34. Everett JR, Hatton IK, Tyler JW. Conformational-analysis of erythromycin a derivatives - a predictive method using NMR chemical-shift and coupling-constant data. Magn Reson Chem. 1990;28(2):114-118.

35. Bender ML, Komiyama M. Cyclodextrin Chemistry. New York, NY: Springer-Verlag; 1978.

36. Lach JL, Cohen J. Interaction of pharmaceuticals with schardinger dextrins II. Interaction with selected compounds. J Pharm Sci. 1963;52(2):137-142.

37. VanEtten RL, Sebatian JF, Clowes GA, Bender ML. Acceleration of phenyl ester cleavage by cycloamyloses: a model for enzymatic specificity. J Am Chem Soc. 1967;89(13):3242-3253.

38. Cramer F, Hettler H. Inclusion compounds of cyclodextrins. Naturwissenschaften. 1967;54(24):625-632.

39. Manor PC, Saenger W. Water molecule in hydrophobic surroundings: structure of a-cyclodextrin-hexahydrate. Nature. 1972;237: 392-393.

40. Guo QX, Liu L, Cai WS, Jiang Y, Liu YC. Driving force prediction for inclusion complexation of alpha-cyclodextrin with benzene derivatives by a wavelet neural network. Chem Phys Lett. 1998; 290(4-6): 514-518.

41. Takeo K, Kuge T. Complexes of starchy materials with organic compounds part III. X-ray studies on amylose and cyclodextrin complexes. Agric Biol Chem. 1969;33:1174-1180.

42. Aree T, Jacob J, Saenger W, Hoier H. Crystal structure of alphacyclodextrin-acetonitrile-hexahydrate. Carbohydr Res. 1998;307(3-4): 191-197.

43. Stigter M, Bezemer J, de GK, Layrolle P. Incorporation of different antibiotics into carbonated hydroxyapatite coatings on titanium implants, release and antibiotic efficacy. J Control Release. 2004;99(1): 127-137.

44. Zhang R, Xu D, Landeryou T, et al. Ectopic bone formation using osteogenic protein-1 carried by a solution precipitated hydroxyapatite. J Biomed Mater Res A. 2004;71(3):412-418.
45. Zhang R, An Y, Toth CA, Draughn RA, Dimaano NM, Hawkins MV. Osteogenic protein-1 enhances osseointegration of titanium implants coated with peri-apatite in rabbit femoral defect. $J$ Biomed Mater Res B Appl Biomater. 2004;71(2):408-413.

46. Butler MN, Weber WJ. Accelerated transformation and deactivation of erythromycin in superheated water. 1 . Temperature effects, transformation rates, and the impacts of dissolved organic matter. Environ Sci Technol. 2005;39(7):2294-2300.

47. Kong YY, Yoshida H, Sarosi I, et al. OPGL is a key regulator of osteoclastogenesis, lymphocyte development and lymph-node organogenesis. Nature. 1999;397(6717):315-323.

48. Lacey DL, Timms E, Tan HL, et al. Osteoprotegerin ligand is a cytokine that regulates osteoclast differentiation and activation. Cell. 1998;93(2): 165-176.

49. Ren W, Wu B, Peng X, Hua J, Hao HN, Wooley PH. Implant wear induces inflammation, but not osteoclastic bone resorption, in RANK(-/-) mice. J Orthop Res. 2006;24(8):1575-1586.

50. Gehrke T, Sers C, Morawietz L, et al. Receptor activator of nuclear factor kappaB ligand is expressed in resident and inflammatory cells in aseptic and septic prosthesis loosening. Scand J Rheumatol. 2003;32(5): 287-294.

51. Greenfield EM, Bi Y, Ragab AA, Goldberg VM, van de Motter RR. The role of osteoclast differentiation in aseptic loosening. J Orthop Res. 2002;20(1):1-8.

52. Sabokbar A, Fujikawa Y, Neale S, Murray DW, Athanasou NA. Human arthroplasty derived macrophages differentiate into osteoclastic bone resorbing cells. Ann Rheum Dis. 1997;56(7):414-420.

53. Irie T, Uekama K. Pharmaceutical applications of cyclodextrins. 3. Toxicological issues and safety evaluation. J Pharm Sci. 1997;86(2): $147-162$.
International Journal of Nanomedicine

\section{Publish your work in this journal}

The International Journal of Nanomedicine is an international, peerreviewed journal focusing on the application of nanotechnology in diagnostics, therapeutics, and drug delivery systems throughout the biomedical field. This journal is indexed on PubMed Central, MedLine, CAS, SciSearch $\AA$, Current Contents ${ }^{\circledR} /$ Clinical Medicine,

\section{Dovepress}

Journal Citation Reports/Science Edition, EMBase, Scopus and the Elsevier Bibliographic databases. The manuscript management system is completely online and includes a very quick and fair peer-review system, which is all easy to use. Visit http://www.dovepress.com/ testimonials.php to read real quotes from published authors. 